\title{
PHOTOSYSTEM II AND CYTOCHROME $b$-559 IN THE STROMA LAMELLAE OF BARLEY CHLOROPLASTS
}

\author{
by \\ OLIVER VALLON ${ }^{1)}$, GUNILLA HØYER-HANSEN and DAVID J. SIMPSON
}

Department of Physiology, Carlsberg Laboratory, Gamle Carlsberg Vej 10, DK-2500 Copenhagen Valby

1) Present address: Department of Cellular and Developmental Biology, The Biological Laboratories, Harvard University, Cambridge, MA 02138 USA

Keywords: Colloidal gold, electron transport, fluorescence emission, immune-blot,
immunocytochemistry, monoclonal antibodies, P700 polypeptides, thylakoids

The presence of photosystem II polypeptides and photosystem II activity in unstacked regions of barley thylakoid membranes were investigated by immunological and spectroscopic techniques. Immunogold labelling of Lowicryl-embedded chloroplasts showed that PSI and the ATPase were completely excluded from stacked regions, while a significant proportion of PSII was located in unstacked regions of the membrane. A membrane fraction derived from stroma lamellae was shown by immuno-blotting to contain PSII components. Their abundance was approximately one tenth (on a chlorophyll basis) of that in the starting material. The stroma lamellae showed a corresponding level of photosystem II-mediated electron transport, in the presence of the electron donor diphenyl-carbazide. Much of the activity was DCMU insensitive, and the reaction centres lacked the antennae pigment CP29, which was located only in appressed thylakoids. Cytochrome $b$-559 LP, but not HP, was present in the stroma lamellae fraction. Evidence is presented that the native low potential form of cytochrome $b-559$ exists as a unique molecular species, distinct from the high potential form (cytochrome $b-559 \mathrm{HP}$ ).

\section{INTRODUCTION}

The thylakoid membrane of chloroplasts is differentiated into stacked and unstacked regions, which constitute separate domains with different compositions and functional properties (review in 47). In the generally accepted model, chloroplastic ATPase and photosystem I (PSI) are located in unstacked regions of the membrane (stroma lamellae and end membranes of grana) $(35,38,50)$, whereas photosystem II (PSII) and its antennae are found mainly in stacked regions $(5,8)$. The cytochrome $f / b$ 563 complex is present in both domains $(1,14)$. Although it is generally accepted that PSI is totally excluded from stacked regions $(6,34)$, the exact extent to which PSII components are segregated within the grana stacks remains unclear $(3,6,40)$.

It has been assumed that the EFu particles of unstacked regions represent PSII centres associated with a small light-harvesting antenna $(7,9)$. Direct evidence for the presence of PSII compo-

Abbreviations: $\mathrm{CF}_{1}=$ coupling factor $1 ; \mathrm{Chl}=$ chlorophyll; $\mathrm{cyt}=$ cytochrome; $\mathrm{DCMU}=3$-(3,4-dichlorophenyl)1,1'-dimethyl urea; DCPIP $=2,6$-dichlorophenol indophenol; $\mathrm{DPC}=1,5$-diphenyl carbazide; $\mathrm{DT}=$ dithionite; $\mathrm{FeCy}=$ ferricyanide; $\mathrm{HP}=$ high potential; $\mathrm{HQ}=$ hydroquinone; $\mathrm{LP}=$ low potential; $\mathrm{mAb}=$ monoclonal antibody; $\mathrm{MD}=$ menadiol; $\mathrm{Mes}=2-(\mathrm{N}$-morpholino $)$-ethanesulphonic $\mathrm{acid} ; \mathrm{pAb}=$ polyclonal antibody; $\mathrm{PS}=$ photosystem . 
nents in unstacked membranes has come from studies using fractionation methods $(3,7,31)$ or immunocytochemistry $(49,50)$. However, several groups have reported the isolation of a stroma lamellae fraction with very little (6) or no PSII activity (18).

In the present study we have analysed the distribution of the two photosystems in barley thylakoids, with particular emphasis on PSII. We have used immunocytochemistry to detect PSII components in situ, and mechanical disruption of thylakoids to isolate a membrane fraction derived from stroma lamellae. The characteristics of the PSII activity in stroma lamellae is described and we present data concerning the nature and function of cytochrome b-559.

\section{MATERIALS AND METHODS}

\subsection{Antibodies}

Polyclonal antibodies (pAb) to the Chlamydomonas reinhardtii polypeptides 5, 6 and 12 (corresponding to $\mathrm{CP} 47, \mathrm{CP} 43$ and the extrinsic $33 \mathrm{kDa}$ polypeptide of PSII, respectively, in higher plants) were provided by N.-H. CHUA (Rockefeller University, N.Y.). The antibody to DI (32 kDa polypeptide) was provided by J. HiRSCHBERG (Hebrew University of Jerusalem, Israel). Monoclonal antibodies were raised by injecting female mice (Balb/c strain, Bomholtgaard, Ry, Denmark) intraperitoneally with the appropriate antigen according to the injection schedule described in (26). Monoclonal antibodies (mAB) used were $\mathrm{CMpChl}_{a}-\mathrm{P} 1: 1$ (E8)(to the PSI large subunit) (24) and 9A12 (to the a-subunit of $\mathrm{CF}_{1}$ ) (23) and $\mathrm{CMpChl}_{a / b}-\mathrm{Pl}: 1$ (1XC3)(to CP29) (25). mAb 6A5 to the $9.2 \mathrm{kDa}$ polypeptide of cytochrome $b-559$ was obtained from a fusion using PSII particles as the antigen.

\subsection{Immuno-blot analysis}

Samples were electrophoresed on 10-20\% polyacrylamide gels containing $6 \mathrm{M}$-urea as in (9), and transferred to nitrocellulose filters according to (48). Immuno-blot assays were carried out using peroxidase and 3-amino-9 ethylcarbazole as in (26).

\subsection{Preparation of the stroma lamellae fraction}

Barley seedlings were grown in vermiculite under continuous light and harvested when 7 days old. Leaves were homogenized in a buffer containing $0.35 \mathrm{M}$-sorbitol, $10 \mathrm{~mm}-\mathrm{MgCl}_{2}$ and 50 mM-morpholinepropane sulphonic acid (Mops), pH 7.5 and the homogenate filtered through 2 layers of $20 \mu \mathrm{m}$ nylon mesh. Chloroplasts were osmotically shocked and disrupted in a French pressure cell as described in (18). The pressate was centrifuged at $40,000 \mathrm{~g}$ for $30 \mathrm{~min}$ in an SS34 rotor and the upper half of the supernatant was carefully removed. For "on grid" labelling and measurement of PSII activity and fluorescence, the supernatant was used as such. For other purposes, it was sedimented at $100,000 \mathrm{~g}$ for $30 \mathrm{~min}$ in a $60 \mathrm{Ti}$ rotor.

\subsection{Electron microscopy}

The "on grid" immuno-labelling technique involved adsorption of thylakoid vesicles prepared by French press treatment onto colloidoncoated grids. They were incubated with antibodies and colloidal gold labelled protein $\mathrm{A}$, with bacitracin in place of bovine serum albumin to prevent non-specific binding. The grids were air-dried and uni-directionally shadowed in a Balzers BAF 301 freeze-etching machine (51). For immunocytochemistry on thin sections, chloroplasts were fixed, embedded in Lowicryl K4M and labelled as previously described (49). Gold sols $(12 \mathrm{~nm})$ were prepared according to (22) and conjugated with protein A for detection of $\mathrm{pAb}$ 's or with a rabbit anti-mouse IgG antibody (DAKO Immunoglobulins A/S, Copenhagen) for detection of mAb's. Quantitation of labelling was done by counting gold particles over appressed thylakoid regions versus non-appressed regions (stroma lamellae and grana end lamellae). The percentage label over stacked regions was obtained by dividing the number of particles over appressed regions by the total number counted. Since appressed membranes accounted for $65 \%$ of the total thylakoids area, the ratio of labelling of non-appressed versus appressed regions was calculated from the following formula: 


$$
\frac{\text { unstacked }}{\text { stacked }}=\frac{100-x}{x} \cdot \frac{65}{35}
$$

where $\mathrm{x}=\%$ label in stacked regions.

\subsection{P700 measurements}

P700 was measured chemically as in (10) using $25 \mu \mathrm{M}$-FeCy to oxidise the sample (instead of $1 \mathrm{~mm}$ ), and $0.5 \mathrm{~mm}$-ascorbate to reduce the reference. After recording the difference spectrum on an Aminco DW-2a, $5 \mu \mathrm{l}$ of $0.1 \mathrm{M}$-ascorbate was added to each cuvette to reduce the oxidised sample, and the difference spectrum was again recorded. In this way, the oxidation of bulk chlorophyll was minimised. P700 was calculated from the difference in OD at $700 \mathrm{~nm}$ using an extinction coefficient of $64 \mathrm{~mm}^{-1}$. Photochemical P700 was measured in the dual beam mode with the reference wavelength at $725 \mathrm{~nm}$ and side illumination with blue light. The photomultiplier tube was protected with a red Schott RG665 cut-off filter.

\subsection{Cytochrome determination}

Isolated thylakoids or stroma lamellae were twice resuspended in $\mathrm{N}_{2}$-purged $50 \mathrm{~mm}$-Mes, $\mathrm{pH}$ 6.0 to a final chlorophyll concentration of about $4 \mathrm{mg} \cdot \mathrm{ml}^{-1}$. They were diluted to between $50-100$ $\mu \mathrm{g}$ chlorophyll $\cdot \mathrm{ml}^{-1}$ in $5 \mathrm{ml}$ for spectroscopic determination of cytochromes. Using an Aminco DW-2a with a $2 \mathrm{~nm}$ slit and a full scale of $0.01 \mathrm{~A}, 1 \mathrm{ml}$ of membrane suspension was added to each cuvette and the baseline corrected from $540-580 \mathrm{~nm}$.

Menadiol was made from menadione according to the method of (41) and was stored in aliquots as a $0.1 \mathrm{~m}$ solution in acidified ethanol at $-196{ }^{\circ} \mathrm{C}$ until required. Stock solutions of 0.1 $\mathrm{M}$-hydroquinone and $5 \%$ dithionite were fresh each day and stored under argon. FeCy was also made fresh each day as a $0.1 \mathrm{M}$ stock. Triton $\mathrm{X}-100$ was added to a final concentration of $1 \%$ from a $25 \%$ stock.

Cytochrome $f$ and $b-559 \mathrm{HP}$ were calculated from the hydroquinone ( $1 \mathrm{mM}$ ) minus $\mathrm{FeCy}(1$ $\mathrm{mm}$ ) spectrum recorded $10 \mathrm{~min}$ after addition of $10 \mu \mathrm{l}$ of the appropriate stock solutions, using the equations:

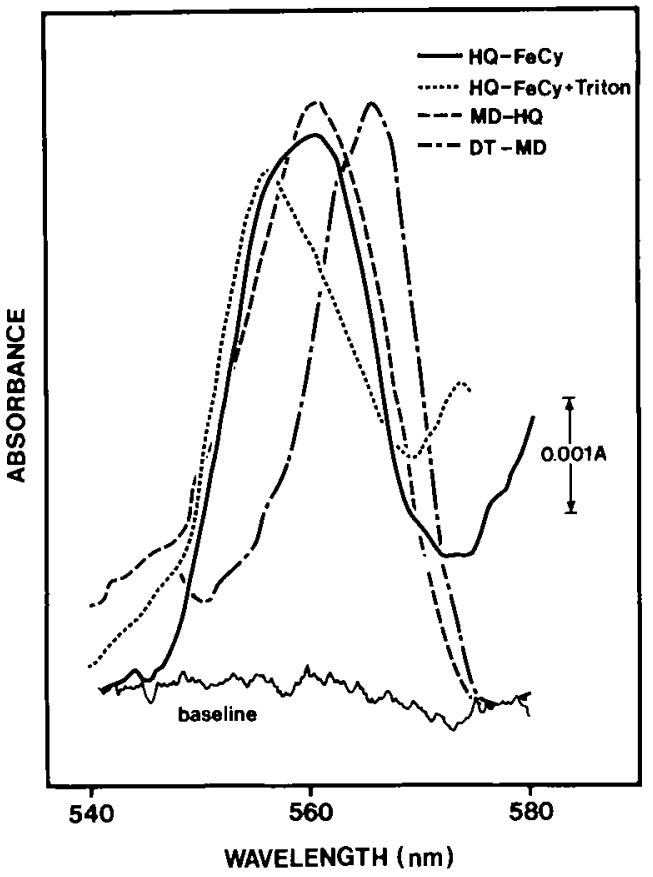

Figure 1. Absorption spectra of cytochromes in isolated thylakoids at room temperature. Cytochrome $b$ $559 \mathrm{HIP}$ and cytochrome $f$ were calculated from the hydroquinone (HQ) minus ferricyanide (FeCy) curve. and cytochrome $f$ from the $\mathrm{HQ}-\mathrm{FeCy}$ curve in the presence of Triton X-100. Cytochrome $b-559$ LP was calculated from the menadiol (MD) minus hydroquinone (HQ) curve, and cytochrome $b-563$ from the dithionite (DT) minus menadiol (MD) curve.

cytochrome $f=57.8 \mathrm{~A}_{552}-14.4 \mathrm{~A}_{560}($ in $\mu \mathrm{M})$ cytochrome $b-559 \mathrm{HP}=52.4 \mathrm{~A}_{560}-9.4 \mathrm{~A}_{552}$

from (11), where the absorbance values are measured with reference to a baseline drawn between the isosbestic points at 538 and $569 \mathrm{~nm}$ (Figure 1). $10 \mu \mathrm{l}$ of Triton X-100 was added to each cuvette, and the concentration of cytochrome $f$ calculated from the absorbance maximum (at $554 \mathrm{~nm}$ ). The following extinction coefficients (11) were used:

cytochrome $f \quad=19.3 \mathrm{mM}^{-1} \cdot \mathrm{cm}^{-1}$ cytochrome $b-563=18.2 \mathrm{mM}^{-1} \cdot \mathrm{cm}^{-1}$ cytochrome $b-559=20.0 \mathrm{mM}^{-1} \cdot \mathrm{cm}^{-1}$ 
A further $1 \mathrm{ml}$ of the membrane suspension was pipetted into each of two cuvettes, together with $10 \mu \mathrm{l}$ of $0.1 \mathrm{M}$-hydroquinone. After $10 \mathrm{~min}$ the corrected baseline was recorded. $10 \mu l$ of 0.1 $M$-menadiol was added to the sample (and a corresponding volume of buffer to the reference cuvette), and the spectrum recorded. This was used to calculate the concentration of cytochrome $b-559 \mathrm{LP}$ from the absorption maximum at $559 \mathrm{~nm}$, with a correction for incomplete reduction (80\%) (42). $10 \mu \mathrm{l}$ of menadiol was added to the reference cuvette and $10 \mu \mathrm{l}$ of $5 \%$ dithionite to the sample. The dithionite minus menadiol spectrum was then recorded and used to calculate the concentration of cytochrome $b-563$ from the maximum at $564 \mathrm{~nm}$ (Figure 1). All concentrations were corrected for dilution effects of the added reagents.

\subsection{Determination of photosystem II activity}

Photosystem II-dependent electron transport rates were determined spectrophotometrically with DCPIP ( $50 \mathrm{~mm}$ ) as the electron acceptor. The extinction coefficient of DCPIP at $590 \mathrm{~nm}$ was determined to be $18 \mathrm{~mm}^{-1} \cdot \mathrm{cm}^{-1}$. Membranes (whole thylakoids, French pressate or stroma vesicles) were diluted to about $20 \mu \mathrm{g}$ $\mathrm{Chl} \cdot \mathrm{ml}^{-1}$ in isolation buffer (section 2.3) and $950 \mu \mathrm{l}$ pipetted into each of two cuvettes. The spectrophotometer was operated with a $5 \mathrm{~nm}$ slit at $590 \mathrm{~nm}$ with a Corning CS 4-96 filter to protect the photomultiplier tube and with illumination through a Schott 2-60 red filter, producing $5000 \mu \mathrm{E} \cdot \mathrm{m}^{-2} \cdot \mathrm{s}^{-1}$ of red light. The electron donor was either water or DPC $(0.5 \mathrm{mM})$. PSIl activity was measured in the presence of the uncoupler $\mathrm{NH}_{4} \mathrm{Cl}(5 \mathrm{mM})$ and its sensitivity to DCMU $(10 \mu \mathrm{M})$ was also determined.

\subsection{Other}

Fuorescence induction kinetics and low temperature fluorescence emission spectra were recorded with the equipment described by (46). Chlorophyll was determined by extracting the membranes in $80 \%$ acetone and using the following equations:

$$
\begin{aligned}
\text { Chl } a & =12.7 \mathrm{~A}_{663}-2.69 \mathrm{~A}_{645}(\text { in } \mu \mathrm{M}) \\
\text { Chl } b & =22.9 \mathrm{~A}_{645}-4.6 \mathrm{~A}_{663} \\
\text { total } \mathrm{Chl} & =\mathrm{A}_{652} \times 1000 / 36
\end{aligned}
$$

\section{RESULTS}

\subsection{Immunogold labelling of barley chloroplasts}

The crude chloroplast preparation contained intact as well as broken chloroplasts. The material was embedded in Lowicryl $\mathrm{K} 4 \mathrm{M}$ and processed for immunogold labelling with antibodies to various thylakoid components. Broken and intact chloroplasts gave similar results, but only the former were used for quantitation of the labelling.

The reaction centre of PSI was localised with $\mathrm{m} \wedge \mathrm{bCMpChl}{ }_{a}-\mathrm{P} 1: 1$, which recognises the large subunit(s) of the PSI reaction centre (24). Labelling was almost exclusively on the non-appressed regions of the membrane (Figure $2 a, b$ ). Background labelling over non-chloroplastic contaminants of the preparation was practically absent. As a further control, immuno-labelling with $\mathrm{CMpChl}_{d}-\mathrm{P} 1: 1$ was performed on plastids of the barley mutant viridis- $z b^{63}$, which is completely devoid of the large PSI reaction centre protein(s) (19,45). Almost no gold labelling was observed on these thylakoids (Figure 2c). The labelling pattern on wild type membranes was quantitated (Table I), and showed only $7.7 \%$ of gold particles in appressed grana regions, representing a 22-fold heavier labelling of stroma lamellae.

The $\mathrm{CF}_{1}$ complex of the ATPase was probed with a mAb which recognises the $\alpha$-subunit (23). As found for PSI, virtually all the label was found on unstacked regions of the membrane (Figure

\begin{tabular}{|c|c|c|}
\hline $\begin{array}{l}\text { Antibody } \\
\text { to }\end{array}$ & $\begin{array}{l}\% \text { label on } \\
\text { stacked regions }\end{array}$ & $\frac{\text { unstacked* }}{\text { stacked }}$ \\
\hline$\alpha-C F_{1}$ & 6.7 & 25.9 \\
\hline $\mathrm{Chl}_{u}-\mathrm{Pl}$ & 7.7 & 22.4 \\
\hline DI & 81.0 & 0.44 \\
\hline CP47 & 80.5 & 0.45 \\
\hline $\mathrm{CP} 43$ & 84.3 & 0.35 \\
\hline $33 \mathrm{kDa} O E E^{\S}$ & 83.3 & 0.37 \\
\hline cyt $b-559$ & 91.2 & 0.18 \\
\hline CP29 & 95.4 & 0.090 \\
\hline
\end{tabular}
2d, Table I). We conclude, in accordance with

Table I. Immunogold labelling of barley thylakoids

* this value gives the relative labelling densities of gold particles on unstacked versus stacked membranes.

s oxygen evolving enhancer polypeptide. 

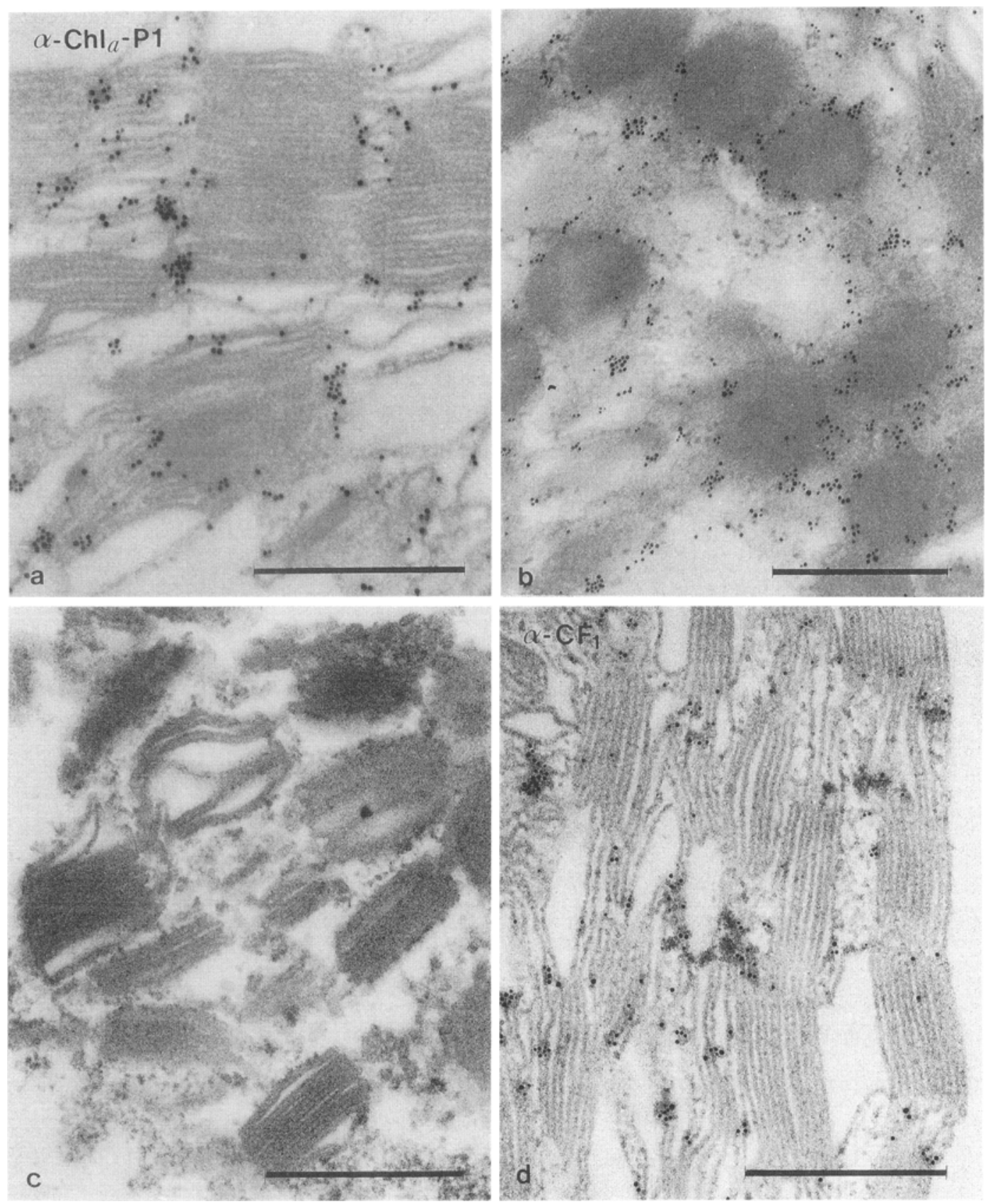

Figure 2. Immunogold labelling of thin sections of isolated thylakoids embedded in Lowicryl K4M. Bars $=0.5 \mu \mathrm{m}$. a. wild type thylakoids incubated with $\mathrm{mAbCMpChl} a-\mathrm{Pl}: 1$ and rabbit anti-mouse IgG antibody (RAM) coupled with $12 \mathrm{~nm}$ colloidäl go gold (G12)'in transverse section. $\times 60,000$.

b. as for (a) with the grana sectioned parallel to the discs. $\times 50,000$.

c. as in (a) with the mutant viridis- $z b^{63} . \times 57,000$

d. wild type thylakoids incubated with a monoclonal antibody against the $a$ subunit of $\mathrm{CF}_{1}$ and labelled with RAM-G12. $\times 57,000$ 

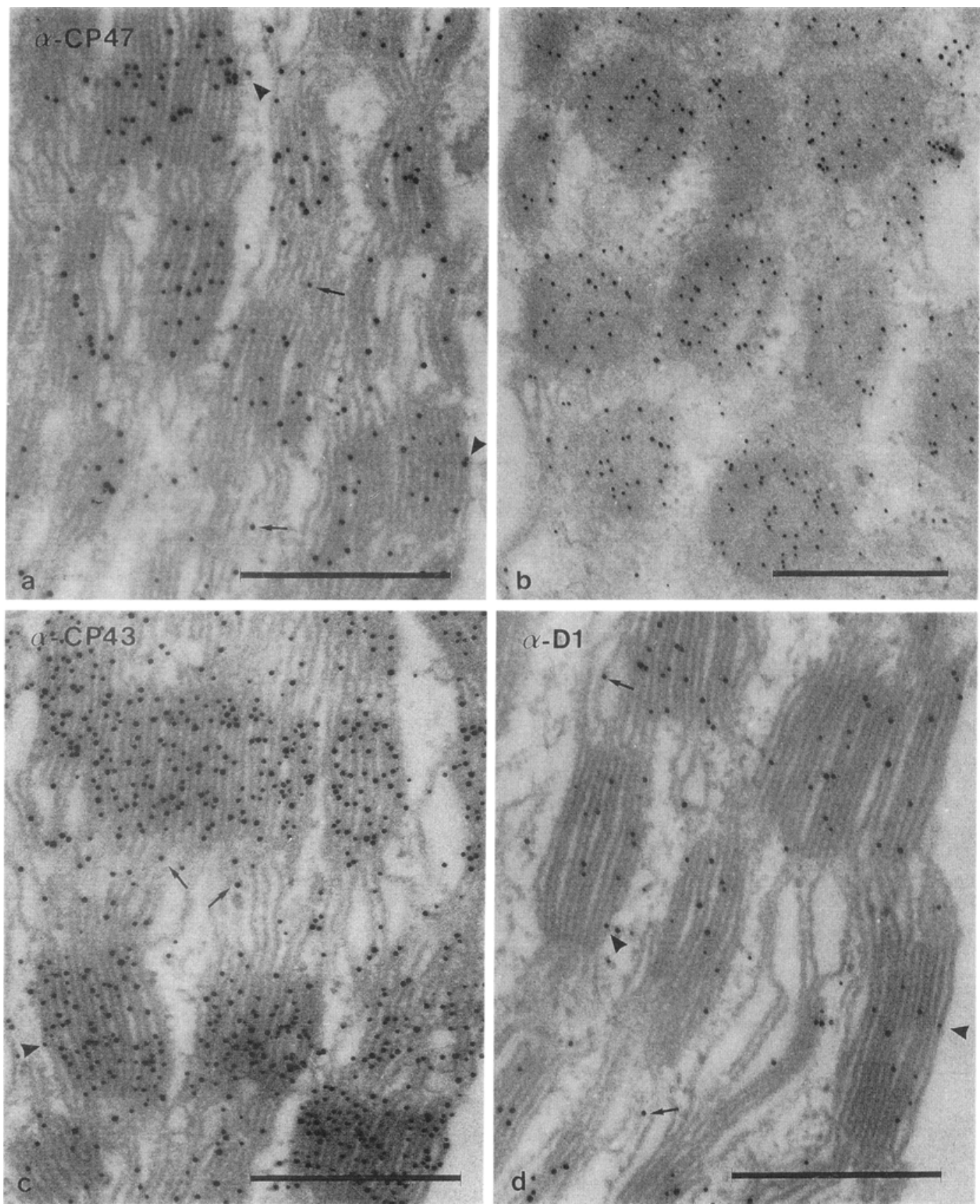

Figure 3. Immunogold labelling of wild type thylakoids with antibodies against photosystem II core polypeptides. Bars $=0.5 \mu \mathrm{m}$.

a. transverse section incubated with $\alpha-5$ (anti-CP47) and labelled with G12 protein A. $\times 60,000$

b. as in (a), cut parallel to the grana discs. $\times 50,000$

c. transverse section incubated with $\alpha-6$ (anti-CP43) and labelled with G12 protein A. $\times 60,000$

d. transverse section incubated with $\alpha$-D1 and labelled with G12 protein A. $\times 60,000$ 

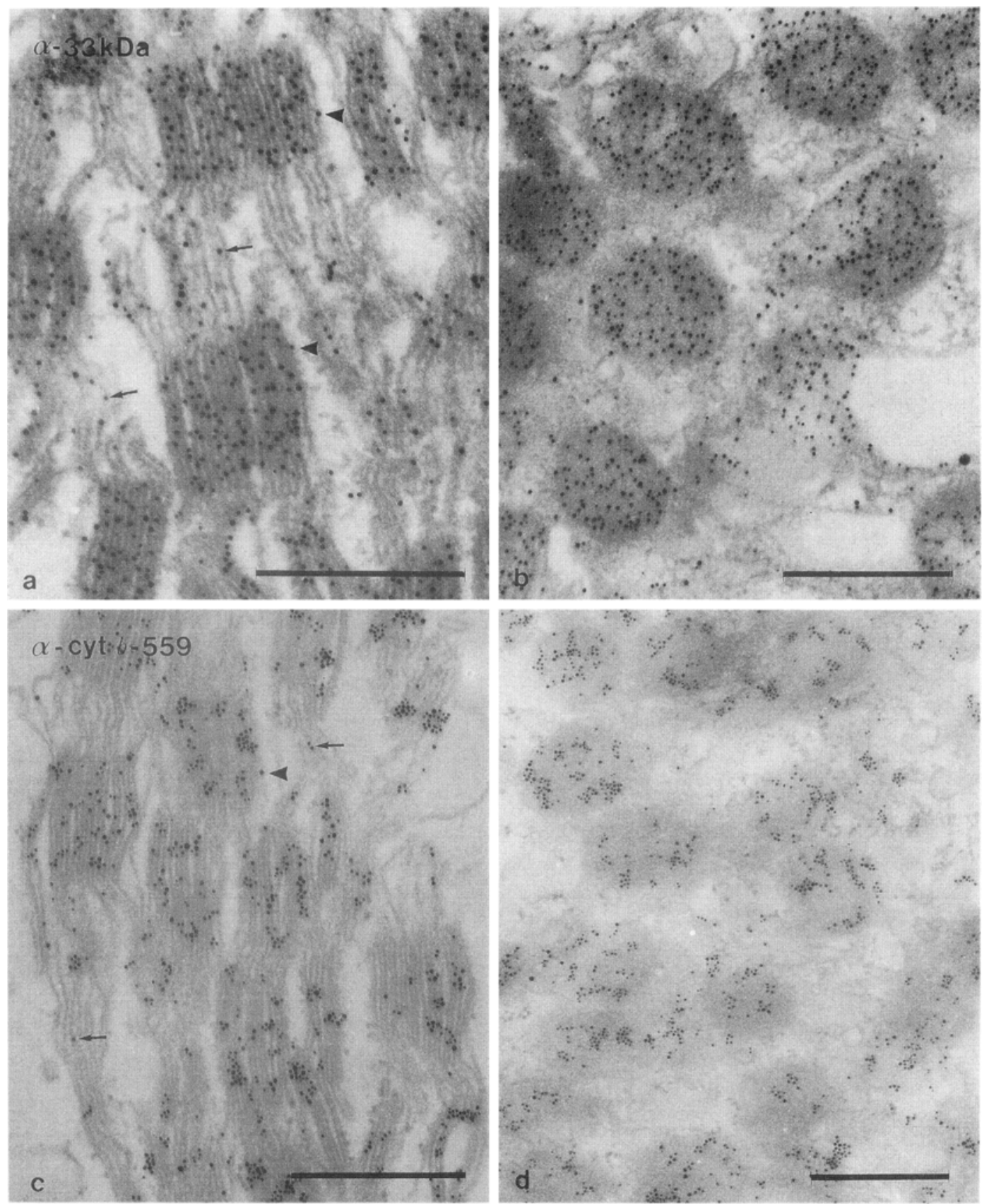

Figure 4. a. Immunogold labelling of a transverse section of wild type thylakoids with antibodies against the $33 \mathrm{kDa}$ oxygen evolving enhancer polypeptide ( $\alpha-12)$ labelled with G12 protein A. $\times 60,000$. Bars $=0.5 \mu \mathrm{m}$.

b. as in (a), sectioned parallel to the grana discs. $\times 50,000$

c. Immunogold labelling of a transverse section of wild type thylakoids with a monoclonal antibody against the $9.2 \mathrm{kDa}$ polypeptide subunit of cytochrome $b-559$, labelled with RAM-G12. $\times 50,000$

$\mathrm{d}$. as in $\mathrm{c}$, sectioned parallel to the grana discs $\times 40,000$ 
previous studies $(35,38,44,50)$, that the PSI reaction centre and the $A T$ Pase $C_{1}$ are totally excluded from the stacked regions of the membrane. The labelling pattern obtained with these antibodies is used as a reference to estimate the degree of segregation of other antigens between appressed and non-appressed membrane regions.

In order to analyse the distribution of PSII reaction centres, sections were labelled with antibodies to various components of the complex. They all gave similar results: pAb's to CP47 (Figure 3a, b), CP43 (Figure 3c), D1 (Figure 3d) and the $33 \mathrm{kDa}$ extrinsic polypeptide (Figure $4 \mathrm{a}$, b), as well as $\mathrm{mAb}(6 \mathrm{~A} 5)$ to the $9.2 \mathrm{kDa}$ polypeptide of cyt $b-559$ (Figure 4c, d), all labelled principally the appressed regions of the membrane (grana stacks). In all cases, however, some labelling was found on the non-appressed regions of the membrane (stroma lamellae arrows and end membranes of grana, arrowheads, Figures 3 and 4). This labelling was significant, as judged by comparison with sections incubated with a non-immune serum, and the viridis- $-b^{63}$ mutant incubated with mAb $\mathrm{CMpChl}_{\alpha}-\mathrm{Pl}: 1$ (Figure 2c). Labelling over the two domains was quantitated for each antibody (Table I). Polyclonal antibodies showed between $80-85 \%$ of label in appressed grana regions, being a 2-3 fold higher labelling density compared with unstacked membranes. The mAb 6A5 to cytochrome $b$-559 gave a more grana-specific labelling pattern, with $91.2 \%$ of gold particles located over appressed regions (Table I). We also examined the distribution of the photosystem II antenna chlorophyll-protein $\mathrm{CP} 29$, using $\mathrm{mAb}$ 1XC3 (25). More than 95\% was located in appressed grana membrane regions, representing a labelling density 11 -fold higher than found in stroma lamellae (Table I). From these data, CP29 is more strictly confined to appressed membranes than PSII core polypeptides.

\subsection{Composition of a membrane fraction derived from stroma lamellae}

In order to study the composition and functional properties of PSII in unstacked regions of the membrane, we isolated a membrane fraction derived from the stroma lamellae of barley

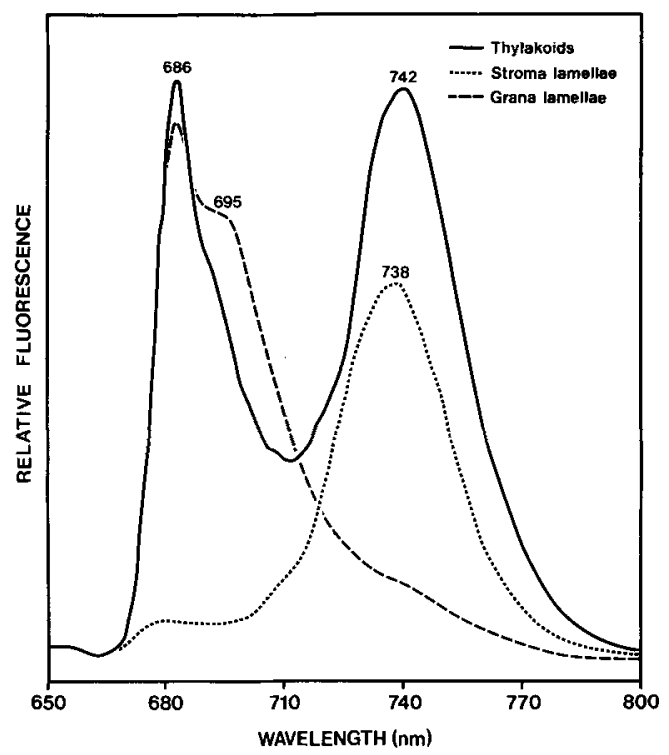

Figure 5. Low temperature ( $77 \mathrm{~K}$ ) fluorescence emission spectra of isolated stroma and grana lamellae. Samples were diluted to $5 \mu \mathrm{g} \mathrm{Chl} \cdot \mathrm{ml}^{-1}$. Grana fragments were prepared according to (12), and the thylakoid spectrum was recorded by the solid dilution technique (52)

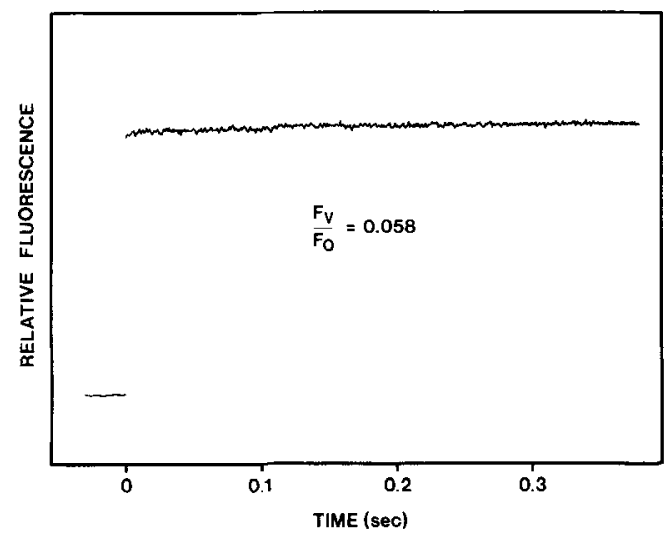

Figure 6. Room temperature fluorescence induction kinetics of isolated stroma lamellae. The variable fluorescence (Fv) after $0.4 \mathrm{~s}$ was only about twice the noise level of the signal. The Fv/Fo ratio was 0.058 , compared with about 5 for whole thylakoids (46), which reach $>90 \%$ of the maximum fluorescence yield (Fm) by $0.4 \mathrm{~s}$ at the light intensity used. 


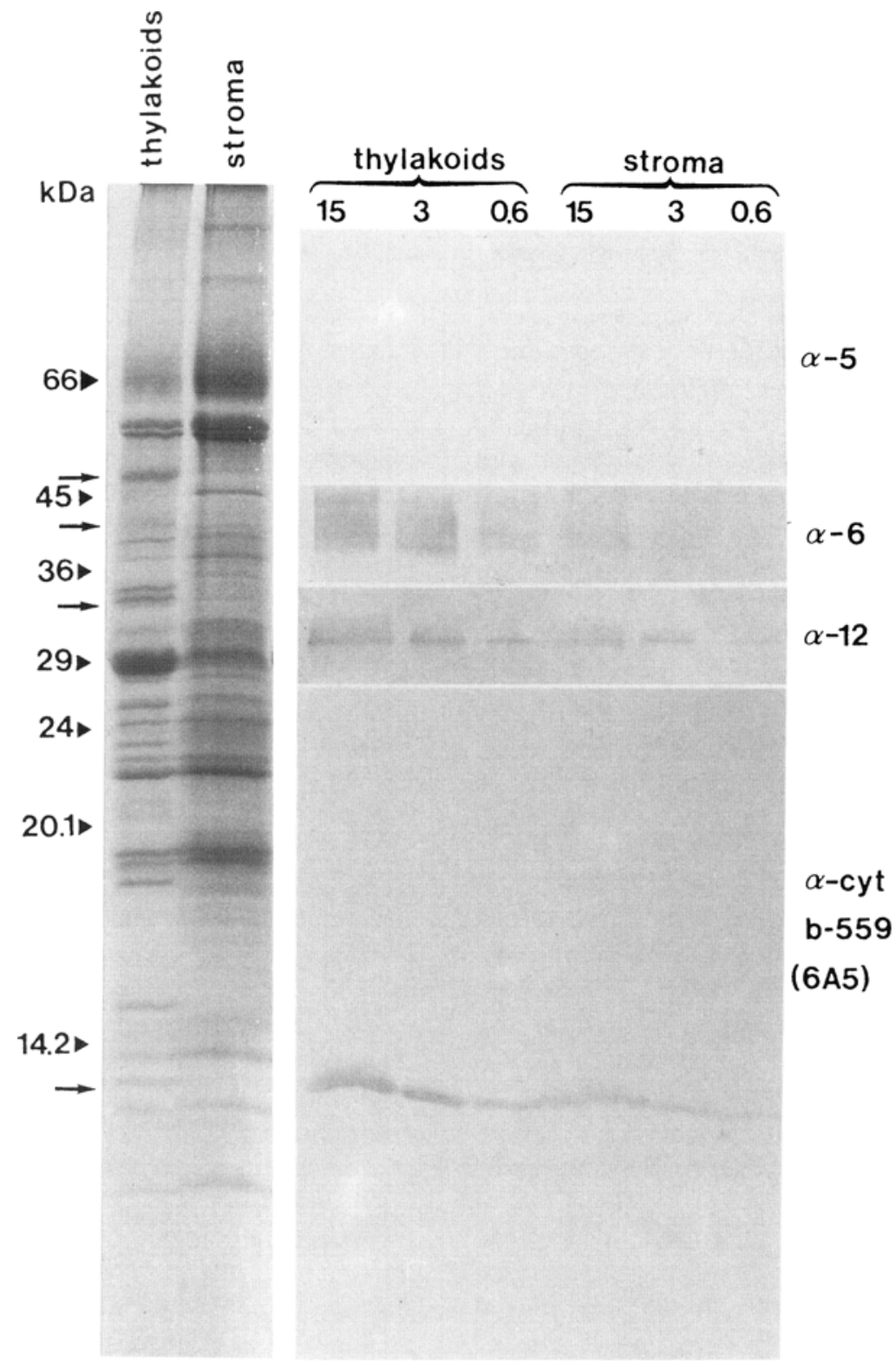

Figure 7. Polypeptide composition of the stroma lamellae fraction. Left two lanes: Coomassie Blue stained gel of thylakoids and stroma lamellae (stroma). The position of the molecular weight markers is indicated on the left. Right hand panel shows the immuno-blot analysis of thylakoids and stroma lamellae. Numbers indicate $\mu \mathrm{g}$ Chl loaded per lane. Blots were reacted with antibodies $\alpha-5$ (to CP47), $\alpha-6$ (to CP43), $\alpha-12$ (to the $33 \mathrm{kDa}$ extrinsic polypeptide) and $6 \mathrm{~A} 5$ (to the $9.2 \mathrm{kDa}$ polypeptide of cyt $b-559$ ) as indicated on the right. Only the relevant parts of the filters are shown. $a-5$ and $\alpha-12$ are shifted upwards and downwards, respectively, for clarity. Arrows indicate the position of the reacting polypeptides in the SDS-polyacrylamide gel.

chloroplasts. The method used is similar to that introduced by (43). Stacked thylakoids are passed through a French pressure cell at 3400 psi. After centrifugation $(40,000 \times \mathrm{g}$ for $30 \mathrm{~min})$, the upper part of the supernatant is carefully removed and used as a stroma lamellae fraction. 
The stroma lamellae fraction was highly enriched in PSI, as judged from the low Chl:P700 ratio $(208 \pm 10$ versus $518 \pm 56$ for the starting material) and high $\mathrm{Chl} a / b$ ratio $(7.4 \pm 0.62)$. This was confirmed from the low temperature fluorescence spectrum of stroma lamellae (Figure 5). Most of the fluorescence was emitted in the far red (peak at $738 \mathrm{~nm}$ ), indicating a marked PSI enrichment. The shoulder at $680 \mathrm{~nm}$ can be taken as indicative of the presence of a small amount of PSII centres, and its area represents $2.4 \%$ of the total emission. As shown in Figure 5 , this peak is prominent in the spectrum of a PSIl-enriched fraction prepared according to (12). From room temperature fluorescence kinetic measurements, variable fluorescence was at the limit of detection (Figure 6): the Fv/Fm ratio was approximately $1 \%$ of that of the starting material.

In Figure 7, the electrophoretic pattern of the stroma lamellae is compared with that of the starting material. The enrichment in PSI and ATPase components is evident, as is a marked depletion of PSII and LHCII polypeptides. In order to estimate the amount of PSII polypeptides present in this preparation, we used a semi-quantitative approach based on immunoblotting with specific antibodies. Proteins from the original thylakoid preparation and the stroma lamellae fraction were separated by SDSPAGE, transferred onto nitrocellulose sheets and reacted with the antibodies (Figure 7; for convenience, only the regions of the blots containing the relevant antigens are shown). Various amounts of chlorophyll were loaded onto each lane, which allows for a direct comparison of the intensities of the immuno-reactions at different loads. The pAb's were raised against $C$. reinhardtii polypeptides, which have different electrophoretic mobilities than their barley counterparts. Thus, any non-specific reactions due to co-migration of other polypeptides would have been obvious.

In the stroma lamellae, the reactions obtained at $15 \mu \mathrm{g} \mathrm{Chl} \mathrm{with} \mathrm{antibodies} \alpha-6$ (to CP43) and $6 \mathrm{~A} 5$ (to the $9.2 \mathrm{kDa}$ polypeptide of cytochrome $b-559$ ), were slightly stronger than those obtained with the starting material at a 25 times lower load. This indicates that, on a chlorophyll basis, stroma lamellae contained around 10 times less (between 5 and 25 times) CP43 and the $9.2 \mathrm{kDa}$ polypeptide of cytochrome $b-559$ than the starting material. CP47 could not be detected in the stroma lamellae at $15 \mu \mathrm{g} \mathrm{Chl} \mathrm{(} \alpha-5$, Figure 7), but the limit of detection in the starting material was at $3 \mu \mathrm{g} \mathrm{Chl}$. This indicates that its abundance in stroma lamellae is less than one fifth of that in the starting material. The same conclusion was reached for polypeptide D1 (data not shown).

From these data, it appears that the intrinsic polypeptides of PSII studied are present in stoichiometric amounts in the stroma lamellae at about one tenth of their level in the starting material. Assuming that the stroma lamellae preparation is representative of the non-appressed membranes, and that the latter account for $35 \%$ of the thylakoid membrane, we estimate that at most, $7 \%$ of PSII reaction centre components are located in non-appressed membranes. The extrinsic $33 \mathrm{kDa}$ polypeptide, however, seemed less depleted in the stroma lamellae (between one half and one fifth, $\alpha-12$, Figure 7). This, however, could be due to its being partially released from the membrane during preparation and trapped in the stroma lamellae during French press treatment. In a previous immunocytochemical study, this polypeptide was not found to be enriched in stroma lamellae with respect to other PSII components (49), as also found from the immunogold labelling in Table I.

The purification procedure used, fractionates membrane fragments according to their size only, and it could be argued that the PSII components observed in our stroma lamellae fraction were the result of a contamination by small grana-derived membrane fragments. We therefore subjected the stroma lamellae fraction to "on grid" immuno-labelling with the $\mathrm{Ab}$ to CP43 (Figure 8). In this technique (51), a membrane preparation is deposited on a plastic film, immuno-labelled and shadowed with platinum. Hence, individual membrane fragments can be analysed for the presence of an antigen. The stroma lamellae preparation appeared to be comprised of small vesicles exclusively. The labelling with $\alpha-6$ (to CP43) was much weaker than in the starting material (see 51), as could be expected from the depletion of the antigen. Interestingly, no vesicle showed the dense la- 

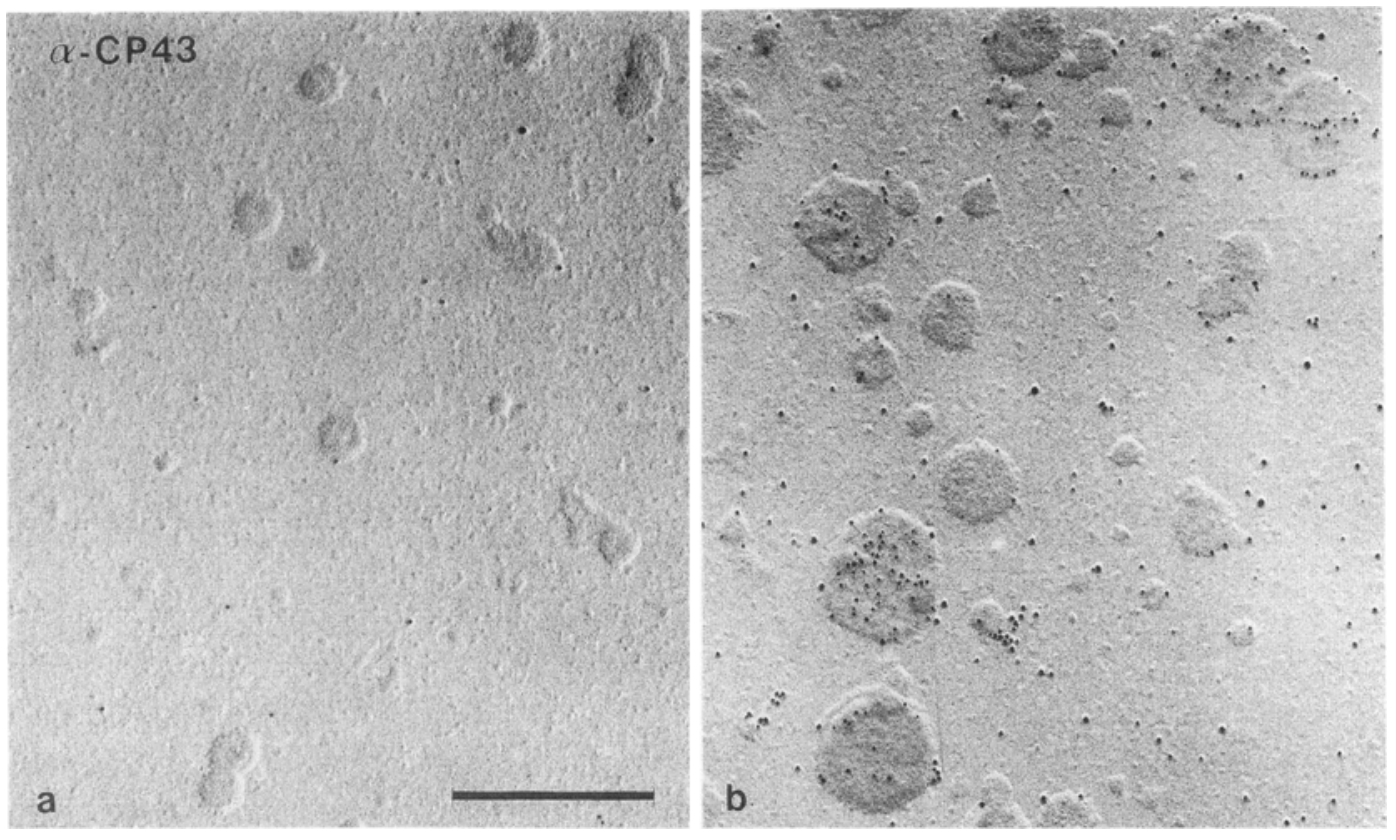

Figure 8. On-grid labelling of (a) stroma lamellae and (b) French pressate with $\alpha-6$ (anti-CP43). Note the small, uniform size of the stroma lamellae vesicles, which have very little label, and compare with the larger, heavily labelled grana lamellae fractions in the French pressate. $\times 20,000$. Bars $=1.0 \mu \mathrm{m}$.

belling that could be expected from a granaderived fragment (Figure 8 ). This can be taken as an indication that the preparation is homogeneous in composition with regard to CP43, and is consistent with freeze-fracture analysis of isolated stroma lamellae (BASSI and SIMPSON, unpublished data), which showed $<0.1 \%$ contamination of isolated stroma lamellae with appressed membranes. The presence of other PSII components could not be directly assessed by this method since our antibodies either did not recognise the barley antigen at either membrane surface, or did so only at the inner surface (not accessible in this preparation).

\subsection{Photosystem II activity in the stroma lamellae fraction}

Thylakoids showed a light-dependent reduction of DCPIP at a rate of about $33 \mu \mathrm{mol} \cdot \mathrm{mg}$ $\mathrm{Chl}^{-1} \cdot \mathrm{h}^{-1}$, with either water or DPC as the electron donor (Table II). These rates are low,

Table II. Photosystem II activity

\begin{tabular}{lccc}
\hline $\begin{array}{l}\text { partial } \\
\text { reaction }\end{array}$ & thylakoids* & $\begin{array}{l}\text { French } \\
\text { pressate }\end{array}$ & $\begin{array}{l}\text { stroma } \\
\text { lamellae }^{\S}\end{array}$ \\
\hline $\mathrm{H}_{2} \mathrm{O} \rightarrow$ DCPIP & 33.1 & 5.6 & 0.38 \\
$\mathrm{DPC} \rightarrow$ DCPIP & 33.8 & 14.8 & 1.30 \\
DCMU inhibition (\%) & 98.2 & 95.5 & 61.0 \\
\hline
\end{tabular}

* values are in $\mu \mathrm{mol}$ DCPIP reduced $\cdot \mathrm{mg} \mathrm{Chl}{ }^{-1} \cdot \mathrm{h}^{-1}$

$\$$ values are underestimated due to non-saturating light (see 31) 
Table III. Composition of barley thylakoids and stroma lamellae

\begin{tabular}{lll}
\hline Component & thylakoids* & stroma lamellae \\
\hline cytochrome $f$ & $1.6 \pm 0.2$ & $1.61 \pm 0.06$ \\
cytochrome $b-563$ & $3.3 \pm 0.2$ & $3.5 \pm 0.7$ \\
cytochrome $b$-559 LP & $3.2 \pm 0.5$ & $2.0 \pm 0.1$ \\
cytochrome $b-559$ HP & $2.4 \pm 0.3$ & $0.004 \pm 0.003$ \\
P700 & $2.2 \pm 0.3$ & $5.2 \pm 0.3$ \\
Chlorophyll $a / b$ & $3.5 \pm 0.1$ & $7.4 \pm 0.6$ \\
\hline
\end{tabular}

* values are in nmoles/mg Chl \pm S.D. (except for $\mathrm{Chl} a / b$ ratio)

but typical for barley grown under low light intensities (20). Assuming one reaction centre for 500 chlorophylls, this corresponds to one turnover every $0.12 \mathrm{~s}$. When the thylakoids were fragmented by French press treatment, water was a poor electron donor. DPC could only restore part of the activity: the DPC-dependent rate was only about half that of the starting material on a $\mathrm{Chl}$ basis (Table II). In isolated stroma lamellae vesicles, a similar enhancement of DCPIP reduction was observed upon addition of DPC. On a Chl basis, the rate of DPC-dependent DCPIP reduction was about $9 \%$ of the French pressate. This may be an underestimate, since the light intensity used was not saturating for stroma lamellae (31). A notable feature of PSII activity in stroma lamellae was its relative insensivity to inhibition by $10 \mu \mathrm{M}$-DCMU (Table II).

\subsection{Nature of the cytochrome $b-559$ signal in stroma lamellae}

Table III shows the cytochrome content of the thylakoid fractions. Cytochromes $f$ and $b-563$ were present in the stroma lamellae at concentrations similar to that in the starting material, reflecting the homogeneous distribution of the cytochrome $f / b-563$ complex in the membrane (1. 2, 14). We could distinguish two pools of cytochrome $h-559$ based on their reducibility by hydroquinone (HP) or menadiol (LP). It is known that cytochrome $b-559 \mathrm{HP}\left(\mathrm{E}_{\mathrm{n} 1}=+370\right.$ $\mathrm{mV}$ ) can be converted to a lower potential form $\left(E_{m}=+110 \mathrm{mV}\right)$ not reducible by hydroquinone $(11,16,42)$. The latter form has been claimed to be measurable by ascorbate reduction, but this has been questioned on the basis of an incom- plete reversibility of the ascorbate/dihydroascorbate system (15). For this reason, no attempt has been made to distinguish this modified form from the native cytochrome $b$-559 LP $\left(E_{m}=+20 \mathrm{mV}\right)$ which has been reported in the membrane (42). Cytochrome $b-559 \mathrm{HP}$ was present in the starting material and French pressate, but was barely detectable in the stroma lamellae. Cytochrome $b$-559 LP, however, was reduced by only $40 \%$ in the stroma lamellae. The data are similar to those obtained by other investigators on similar preparations $(2,14)$.

We addressed the question whether cytochrome $b-559 \mathrm{LP}$ is the same molecular species as cytochrome $b-559 \mathrm{HP}$ (its low mid-point potential then reflecting its being in a different environment), or whether it actually represents a distinct cytochrome. In the first hypothesis, the sum of HP and LP signals in starting material and stroma lamellae, respectively, should correlate with the amount of $9.2 \mathrm{kDa}$ polypeptide (which carries cytochrome $b-559 \mathrm{HP}$ ) in the two preparations. As mentioned above, the $9.2 \mathrm{kDa}$ polypeptide was depleted about 10 times in the stroma lamellae fraction (Figure 7, Table I), whereas the total cytochrome $b-559$ signal (HP + LP) in this fraction was only 3 times lower than that in the starting material. Assuming that the LP and HP forms have similar extinction coefficients, this indicates that the $9.2 \mathrm{kDa}$ polypeptide cannot carry all of the cytochrome $b-559$. To account for these data, we postulate the presence of two distinct cytochromes with an $\alpha$-peak at $559 \mathrm{~nm}$ in thylakoids, one of them carrying the HP cytochrome, the other being constantly LP, each consisting of immunologically distinct polypeptides. 


\section{DISCUSSION}

In the present study, we have quantitatively analysed the distribution of PSII centres between appressed and non-appressed regions of the thylakoid membrane. We used immunogold labelling to detect the polypeptides in situ and French press treatment to isolate a membrane preparation derived from non-appressed lamellae. By immunolabelling with pAb's, the density of PSIl core polypeptides in non-appressed regions was found to be 2-3 times lower, on a membrane area basis, than that found in the appressed regions. However, when the stroma lamellae fraction was analysed by immunoblotting, a substantially lower amount of PSII was found (5-25 times lower, on a Chl basis). It is reasonable, however, to postulate that the membrane fraction we isolated is representative of the non-appressed regions as a whole, since freezefracture electron microscopy reveals only two distinct membrane domains in the thylakoid. The reason for this discrepancy can be found in the intrinsic limitations of the immunogold labelling technique.

The level of labelling observed on non-appressed membranes with PSII Ab's depends upon two factors: the actual level of background labelling (i.e., not due to the antigen), and our ability to attribute each gold particle to the correct domain. Background labelling with the polyclonal antibodies, although low, is bound to lead to an overestimation of the relative amount of PSII in non-appressed regions. This limitation is circumvented by the use of mAb's, which yield practically no background (compare Figures $2 \mathrm{a}$ and $2 \mathrm{c}$ ). In this respect, it should be noted that mAb 6A5 (to cytochrome $b-559$ ) was the most grana-specific of the antibodies against PSII core polypeptides. The distribution observed with this antibody is closer to the distribution of the antigen in vivo, and is more consistent with the immunoblot results.

Even in the absence of non-specific labelling, misattribution of label to one domain, represents a further limitation to the conclusions that can be drawn regarding the presence of PSII antigens in unappressed regions. This is due to the distance between the gold particle and the antigen, which can be up to $30 \mathrm{~nm}$ with a $20 \mathrm{~nm}$ probe $(O$. VALLON, These de l'Université $P$. et $M$.
Curie). It leads to an underestimation of the degree of segregation of the antigen, accounting for some of the slight labelling of appressed membranes with mAb's to the PSI reaction centre and the ATPase $\mathrm{CF}_{1}$ (Table I). The lower levels of PSII components obtained by immunoblotting of stroma lamellae can therefore be expected to be closer to their real distribution.

The fact that immunoblotting and measurement of DCPIP reduction in stroma lamellae gave consistent results, seems to indicate that most of the PSII components in stroma lamellae are assembled into functional reaction centres. A strict correlation between polypeptide levels and PSII reaction centres requires two conditions: that the loss of activity after French pressing should equally affect PSII in appressed and non-appressed membranes and that PSII centres should be homogenous in their efficiency in reducing DCPIP. Some heterogeneity among PSII acceptors has long been recognised $\left(Q_{1}=B\right.$ type and $Q_{2}=$ non- $B$ type $)$, but these two types of acceptors were thought to belong to the same centres $(27,29)$. Recently GRAAN and ORT proposed that up to $40 \%$ of PSII are incapable of reducing plastoquinone at physiological rates (17).

It has also been suggested $(32,33)$, based on fluorescence induction kinetics, that PSII reaction centres are heterogeneous with respect to their rate of photon trapping. The PSII $\alpha$ centres are reduced about 3 times faster than the PSII $\beta$ centres when illuminated in the presence of DCMU. This is attributed to the absence of the peripheral chlorophyll $a / b$ light-harvesting antennae from PSII $\beta$ centres (31) and to the differential sensitivity of PSII $\alpha$ and $\beta$ centres to DCMU (21). Fractionation studies with isolated thylakoids have shown that PSII $\alpha$ centres are located exclusively in appressed grana membranes, while PSII $\beta$ centres are located exclusively in stroma lamellae (3), although damaged PSII $\alpha$ centres in grana behave like PSII $\beta$. It has been proposed that the PSII $\alpha$ centres derive from the PSII $\beta$ centres in the stroma lamellae by the addition of light-harvesting chlorophyll $a / b$ proteins and the development of the ability to reduce plastoquinone (32), and then move into the appressed grana regions. This model would be consistent with our results regarding the 
location of almost all of the CP29 in the grana, where it would be part of the PSII $\beta$ centres.

Relevant to the question of PSII heterogeneity is the finding (Table II) that DCPIP reduction in isolated stroma lamellae is partially insensitive to inhibition by $10 \mu \mathrm{m}$ DCMU. DCMU insensitivity is commonly observed in detergent-solubilised preparations (e.g., 53) and is attributed to damage of the acceptor side. In the present case, however, it was also noted, although at a lower rate, in the intact thylakoid preparation and in the French press homogenate, and is therefore not likely to be an artefact of the preparation procedure. With a stacking ratio of $65 \%$, it can be calculated that all the DCMU-insensitive PSII electron transfer activity is located in unstacked regions. PSII centres in isolated stroma lamellae account for approximately $5 \%$ of the PSII reaction centres in barley grown at 1700 lux, apparently lack 685 and 695 fluorescence emission peaks at $77 \mathrm{~K}$, produce no variable fluorescence at room temperature in the absence of artificial electron donors (see 3 ), and contain no CP29 or cytochrome $b-559 \mathrm{HP}$. In this latter respect they are similar to the inactive PSII centres in bundle sheath membranes of maize, sorghum (4) and other $\mathrm{C}_{4}$ plants with agranal bundle sheath chloroplasts. Their thylakoids, whose freeze-fracture ultrastructure resembles that of stroma lamellae (36), do not contain the DI polypeptide, and do not bind DCMU (44), in contrast to the inactive PSII centres of $\mathrm{C}_{3}$ chloroplasts (17).

Studies on cytochrome $b-559$ are hindered by a lack of knowledge of its function. The high potential form is intimately associated with PSII, and forms a component of the smallest functional PSII particle, which contains only two other polypeptides (37). Synechocystis mutants lacking one or both of the cytochrome $b-559$ genes (psbE and psbF) are incapable of PSII-dependent photochemistry (39), although the presence of D1 and D2 was not determined. The high potential form, with a midpoint redox potential $\left(E_{\mathrm{m}}\right)$ at $\mathrm{pH} 7$ of $+370 \mathrm{mV}$, can be reversibly converted to a low potential form with an $E_{m}$ at $p H 7$ of $+110 \mathrm{mV}(42)$. This conversion, which can be effected by a variety of treatments, is usually, but not necessarily associated with a loss of oxygen evolving capacity $(13,15)$. This low potential form $\left(E_{m}=+110 \mathrm{mV}\right)$ is often confused with a native low potential form of cytochrome $b-559$, whose spectrum is identical to cytochrome $b-559 \mathrm{HP}$, but which has an $\mathrm{E}_{\mathrm{m}}$ at $\mathrm{pH} 7$ of $+20 \mathrm{mV}(16,42)$. This native cytochrome $b$-559 LP has also been found in grana partitions $(2,14)$ and has been reported in purified PSII preparations from the dithionite minus acorbate spectrum (53).

Our results with the mAb against the $9.2 \mathrm{kDa}$ polypeptide of cytochrome $b-559$ show that the latter is located mainly in grana partitions, only $8.8 \%$ being found in stroma lamellae by immunogold labelling (Table I). Immunoblot results from isolated stroma lamellae gave the same results. There was sufficient cytochrome $b$-559 LP in stroma lamellae (Table III) to account for $19 \%$ of the total cytochrome $b-559$, which is more than twice the amount measured immunologically. Therefore, our results demonstrate the existence of a native cytochrome $b-559$ LP which is antigenically distinct from the PSII-associated HP form. Cytochrome $b$-559 LP has been found in both appressed and non-appressed thylakoids (2, 14, this study), and does not appear to be associated with any of the known supramolecular complexes of the thylakoid membrane. It is present in mutants lacking PSI (19), the cytochrome $f / h-563$ complex (11) and PSII (SIMPSON and VALLON, unpublished data). Possible candidates for cytochrome b-559 LP are haem-staining polypeptides at about $32 \mathrm{kDa}$ in barley (28) and 34 and $11 \mathrm{kDa}$ in Chlamydomonas (30).

\section{ACKNOWLEDGEMENTS}

We wish to thank Professors D. vON WETT. STEIN. B.L. Møller. W.A. Cramer and Dr. D.S. BENDALI. for fruitful discussions during the course of this work, and Dr. F.A. WOLLMAN for critically reading the manuscript. We are grateful for the expert technical assistance provided by $T$. BEKTVED in the maintenance of monoclonal antibodies, and thank J. SAGE for skilful technical assistance in immunogold labelling of thin sections. We also thank CLAUS BAHR and ULLA EDEN of the Genetisk Institut, University of Copenhagen, for the use of their electron microscope facilities. 


\section{REFERENCES}

1. Allred. D. R. \& L. A. Staehelin: Lateral distribution of the cytochrome $b 6 / f$ and coupling factor ATP synthetase complexes of chloroplast thylakoid membranes. Plant Physiol. 78, 199-202 (1985)

2. ANDERSON. J. M.: Distribution of the cytochromes of spinach chloroplasts between the appressed membranes of grana stacks and stroma exposed thylakoid regions. FEBS Lett. 138, 62-66 (1982)

3. ANDERSON. J. M. \& A. MELIS: Localization of different photosystems in separate regions of chloroplast membranes. Proc. Natl. Acad. Sci. USA 80, 745-749 (1983)

4. ANderson. J. M.. K. C. WOO \& N. K. BoARdman: Photochemical systems in mesophyll and bundle sheath chloroplasts of $\mathrm{C}_{4}$ plants. Biochim. Biophys. Acta 245, 398-408 (1971)

5. ANDERSSON. B.\& J. M. ANDERSON: Lateral heterogeneity in the distribution of chlorophyll-protein complexes of the thylakoid membranes of spinach chloroplasts. Biochim. Biophys. Acta 593, $427-$ 440 (1980)

6. ANDERSSON. B.\& W. HAEHNE1:: Location of photosystem I and photosystem II reaction centres in different thylakoid regions of stacked chloroplasts. FEBS Lett. 146, 13-17 (1982)

7. ARmond. P. A. \& C. J. ARNTZEN: Localization and characterization of photosystem II in grana and stroma lamellae. Plant Physiol. 59, 398-404 (1977)

8. Armond. P. A.. L. A. Staehelin \& C. J. Arntzen: Spatial relationship of photosystem I, photosystem II and the light-harvesting complex in chloroplast membranes. J. Cell Biol. 73, 400-418 (1977)

9. BASSI. R. U. HINZ \& R. BARBATO: The role of the light-harvesting complex and photosystem II in thylakoid stacking in the chlorina- 2 barley mutant. Carlsberg Res. Commun. 50, 347-367 (1985)

10. B.ASSI. R. \& D. J. SIMPSON: Chlorophyll-protein complexes of barley photosystem I. Eur. J. Biochem. 163, 221-230 (1987)

11. Bendall. D. S. \& S. A. RolfF: Characterisation of chloroplast cytochromes. Manuscript submitted (1987)

12. Berthold. D. A. G. T. BabCOCK \& C. F. Yocum: A highly resolved, oxygen-evolving photosystem II preparation from spinach thylakoid membranes. EPR and electron transport properties. FEBS Lett. 134, 231-234 (1981)

13. Briantais. J. -M.. C. Vernotte. M. Miyad, N. MuRATA \& M.PICAUD: Relationship between $\mathrm{O}_{2}$ evolution capacity and cytochrome b-559 high-potential form in photosystem II particles. Biochim. Biophys. Acta 808, 348-35I (1985)

14. COX, R. \& B. ANDERSSON: Lateral and transversal organization of cytochromes in the chloroplast thylakoid membrane. Biochem. Biophys. Res. Commun. 103, 1336-1342 (1981)

15. Cox. R. P. \& D. S. Bendall: The effect on cytochrome b-559 HP and P546 of treatments that inhibited oxygen evolution by chloroplasts. Biochim. Biophys. Acta 283, 124-135 (1972)

16. Cramer. W. A. \& J. Whitmarsh: Photosynthetic cytochromes. Ann. Rev. Plant Physiol. 28, 133172 (1977)

17. GRAAN.T.\& D.R.ORT: Detection of oxygen-evolving photosystem II centres inactive in plastoquinone reduction. Biochim. Biophys. Acta 852 , 320-330 (1986)

18. He.NRy. L. E. A. \& B. L. MøLler: Polypeptide composition of an oxygen-evolving photosystem II vesicle from spinach chloroplasts. Carlsberg Res. Commun. 46, 227-242 (1981)

19. Hiller. R. G. B. L. Møller \& G. Høyer-Hansen: Characterization of six putative photosystem I mutants in barley. Carlsberg Res. Commun. 45 , 315-328 (1980)

20. Hinz. U.G.: Isolation of the photosystem II reaction center complex from barley. Characterization by circular dichroism spectroscopy and amino acid sequencing. Carlsberg Res. Commun. 50, 285-298 (1985)

21. Hodges. M. \& J. BARBER: The significance of the kinetic analysis of fluorescence induction in DCMU-inhibited chloroplasts in terms of photosystem 2 connectivity and heterogeneity. FEBS Lett. 160, 177-181 (1983)

22. HORISBERGER. M.: Evaluation of colloidal gold as a cytochemical marker for transmission and scanning electron microscopy. Biol. Cellulaire 36, 253258 (1979)

23. HønberG, L. S. : Monoclonal antibodies to components of photosystem I and II. Cand. scient. thesis, Copenhagen University (1985)

24. Høyer-Hansen. G.: Monoclonal antibodies to chlorophyll $a$-protein 1 in barley. In: Advances in Photosynthesis Research (C. Sybesma, ed. ) Vol. III, 2, pp. 171-174. M. Nijhoff - Dr. W. Junk Publ., The Hague. Netherlands (1983)

25. Høyer-Hansen. G.. R. Bassi. L. S. HønberG \& D. J. SIMPSON: Immunological characterization of chlorophyll $a / b$-binding proteins of barley thylakoids. Planta. In press (1987)

26. Jolıot, P. \& A. Jolıot: Evidence for a double hit process in photosystem II based on fluorescence studies. Biochim. Biophys. Acta 462, 559-574 (1977)

27. Høyer-Hansen.G., L. S. Hønberg \& D. J. Simpson: Monoclonal antibodies used for the characterization of the two putative iron-sulfur centre proteins 
associated with photosystem I. Carlsberg Res. Commun. 50, 23-35 (1985)

28. KoENIG, K \& B. L. MøLlER: Isolation and characterization of cytochrome $b-559$ from chloroplasts and etioplasts of barley. Carlsberg Res. Commun. 47, 245-262 (1982)

29. Lavergne, J.: Mode of action of 3-(3,4dichlorophenyl)-1,1'-dimethylurea. Biochim. Biophys. Acta 682, 345-353 (1982)

30. Lemaire, C., J. Girard-Bascou, F. -A. Wollman \& P. BENNOUN: Studies on the cytochrome $b_{6} / f$ complex. I. Characterization of the complex subunits in Chlamydomonas reinhardtii. Biochim. Biophys. Acta 851, 229-238 (1986)

31. MÄenpäÄ. P.. B. Andersson \& C. Sundby: Difference in sensitivity to photoinhibition between photosystem II in the appressed and nonappressed thylakoid regions. FEBS Lett. 215, 31-36 (1987)

32. MELIS, A.: Functional properties of photosystem $\mathrm{II}_{\beta}$ in spinach chloroplasts. Biochim. Biophys. Acta 808, 334-342 (1986)

33. Melis, A.\& P. H. Homann: Kinetic analysis of the fluorescence induction in 3-(3,4-dichlorophenyl)1,1-dimethylurea poisoned chloroplasts. Photochem. Photobiol. 21, $431-437$ (1975)

34. Melis. A., P. Svensson \& P. A. Albertsson: The domain organization of the chloroplast thylakoid membrane. Localization of photosystem I and of the cytochrome b6-f complex. Biochim. Biophys. Acta 850, 402-412 (1986)

35. MilLeR, K. R: A chloroplast membrane lacking photosystem I. Changes in unstacked membrane regions. Biochim. Biophys. Acta 592, 143-152 (1980)

36. Miller, K. R., G. J. Miller \& K. R. MCINTyre: Organization of the photosynthetic membrane in maize mesophyll and bundle sheath cells. Biochim. Biophys. Acta 459, 145-156 (1977)

37. Namba, O.\& K. SATOH: Isolation of a photosystem II reaction center consisting of D1 and D2 polypeptides and cytochrome b-559. Proc. Natl. Acad. Sci. USA 84, 109-112 (1987)

38. Olesko, S. \& E. N. Moudrianakis: The visualization of the photosynthetic coupling factor in embedded spinach chloroplasts. J. Cell Biol. 63, 936-948 (1974)

39. PAKRasi, H. R., J. G. K. Williams \& C. J. ARnTzen: Genetically engineered cytochrome b559 mutants of the cyanobacterium Synechocystis 6803. In: Progress in Photosynthesis Research, (J. Biggins, ed. ) vol. IV, pp. 813-816, Martinus Nijhoff Publ., Dordrecht, Netherlands (1987)

40. RaO, L. V. M.. P. Usharani, W. L. Butler \& K. T. TOKUYASU: Localization of cytochrome b-559 in the chloroplast thylakoid membranes in spinach.
Plant Physiol. 80, 138-141 (1986)

41. Rich. P. R.: Quinol oxidation in Arum maculatum mitochondria and its application to the assay, solubilisation and partial purification of the alternative oxidase. FEBS Lett. 96, 252-256 (1978)

42. Rich. P. R. \& D. S. BENDALL: The redox potentials of the b-type cytochromes of higher plants chloroplasts. Biochim. Biophys. Acta 591, 153-16(1980)

43. Sane, P. V.. D. J. GoOdChILd \& R. B. PARK: Characterization of photosystem I and II separated by a non-detergent method. Biochim. Biophys. Acta 216, 162-178 (1970)

44. Schuster. G. I., I. Ohad, B. Martineau \& W. C. TAYLOR: Differentiation and development of bundle sheath and mesophyll thylakoids in maize. Thylakoid polypeptide composition, phosphorylation and organization of photosystem II. J. Biol. Chem. 260, 11866-11873 (1985)

45. Simpson, D. J.: Freeze-fracture studies on barley plastid membranes. VI. Location of the P700 chlorophyll $a$-protein 1. Eur. J. Cell Biol. 31, 305-314 (1983)

46. Simpson, D. J.\& D. von WetTSTEIN: Macromolecular physiology of plastids XIV. Viridis mutants in barley: genetic, fluoroscopic and ultrastructural characterisation. Carlsberg Res. Commun. 45, 283-314 (1980)

47. Staehelin. L. A.\& M. DE Wit: Correlation of structure and function in the thylakoid membrane at the supra-molecular level. J. Cell Biochem. 24, 261-269 (1984)

48. Towbin. H., T. Staehelin \& J. Gordon: Electrophoretic transfer of proteins from polyacrylamide gels to nitrocellulose sheets: procedure and some applications. Proc. Natl. Acad. Sci. USA 76, 4350-4354 (1979)

49. Vallon, O.. F. A. Wollman \& J. Olive: Distribution of intrinsic and extrinsic subunits of the PSII protein complex between appressed and non-appressed regions of the thylakoid membrane: An immunocytochemical study. FEBS Lett. 183, 245250 (1985)

50. Vallon, O., F. A. Wollman \& J. Olive: Lateral distribution of the main protein complexes of the photosynthetic apparatus in Chlamydomonas reinhardtii and in spinach: an immunocytochemical study using intact thylakoid membranes and a PSII-enriched membrane preparation. Photobiochem. Photobiophys. 12, 203-220 (1986)

51. Vallon, O., F. A. Wollman \& J. Olive: Immunocytochemical studies on the organization of thylakoid membrane components. In: Progress in Photosynthesis Research, (J. Biggins ed. ), Vol II, pp. 329-332, Martinus Nijhoff Publ, Dordrecht, Netherlands (1987) 
O. VALlon et al.: Photosystem II in stroma lamellae

52. WeIS.E: Chlorophyll fluorescence at $77 \mathrm{~K}$ in intact leaves: Characterization of a technique to eliminate artifacts related to self-absorption. Photosyn. Res. 6, 73-86 (1985)
53. Yamada, Y..X. -S. TANG, S. ITOH \& K. Satoh: Purification and properties of an oxygen-evolving photosystem II reaction-center complex from spinach. Biochim. Biophys. Acta 891, 129-137 (1987)

Accepted by E. Lund 